\title{
Análise cultural do torrão dos infernos: imaginário do mal nas poéticas de Dante Milano e \\ Nauro Machado
}

Texto dedicado à psicanalista Adriana Cajado Costa (1973-2012), esposa do autor, falecida neste ano

Alexandre Fernandes Corrêa ${ }^{1}$

A análise cultural sobre o imaginário literário do mal, apresentada neste ensaio, incide sobre aspectos simbólicos destacados nas poéticas dos escritores Dante Milano ${ }^{2}$ (1899-1991) e Nauro Machado 3 (1935). Este estudo complementa temas abordados em outros textos nos quais investigamos a história cultural do signo do mal na cultura brasileira ${ }^{4}$. Por conseguinte, o presente trabalho consiste em mais uma incursão interpretativa nessas duas literaturas produzidas em estados da federação distantes geograficamente - Rio de Janeiro e Maranhão - mas que possuem ressonâncias temáticas admiráveis, nos permitindo perceber variantes importantes da expressão do imaginário do mal à brasileira ${ }^{5}$. De uma grande variedade de temas poéticos explorados pelos dois escritores em tela os que mais nos interessam, aqui nesta análise particular, são os elementos literários constituintes - sobressalentes nas respectivas produções artísticas - vinculados à recorrência dos significantes "amor", "sonho", "morte" e "mal".

\footnotetext{
${ }^{1}$ Doutor em antropologia e professor do Departamento de Sociologia e Antropologia da Universidade Federal do Maranhão, São Luiz (MA), Brasil. E-mail: alexandre.correa@pq.cnpq.br .

${ }^{2}$ Poeta carioca considerado um dos cinco maiores literatos do Modernismo brasileiro. Publicou um único livro, em 1948, com o qual recebeu o prêmio Felipe de Oliveira. Seu livro Poesia e prosa teve várias edições, com adições de textos e poemas inéditos, culminando com o prêmio Machado de Assis da Academia Brasileira de Letras de 1988. No decorrer deste texto encontram-se mais detalhes sobre o seu trajeto biográfico.

3 Poeta maranhense de vasta obra literária, nascido em São Luís em 1935. Autodidata com conhecimento em artes, especialmente cinema e filosofia. Produz poesia com sotaque coloquial, desenvolvendo temas universais e destacando-se entre seus contemporâneos mais imediatos, como Ferreira Gullar, Lago Burnett, José Chagas e Bandeira Tribuzi. Seus poemas questionam a essência e destinação do ser humano, cultivando apurada linguagem poética e técnica de versos. Sua obra apresenta traços de reflexão existencial angustiada e violenta, encontrando poucas comparações na lírica de língua portuguesa. Trabalhou em diversos órgãos públicos, entre eles a Secretaria de Cultura do Estado do Maranhão. Nauro Machado vive em São Luís, de onde se ausentou apenas por breves períodos, especialmente para o Rio de Janeiro, publicando nessa cidade boa parte de suas obras. Amealhou prêmios da Academia Brasileira de Letras (1999) e da União Brasileira de Escritores (2000); possui várias obras traduzidas para o alemão, francês e inglês.

${ }^{4}$ Textos publicados na obra Museu mefistofélico (Corrêa, 2009), em revistas especializadas e em anais de congressos de Antropologia e Sociologia.

${ }^{5}$ Expressão usada originalmente no livro, organizado por Patrícia Birman, O mal à brasileira (1997).
} 
Ver-se-á que não se trata de uma aproximação forçada pela imaginação do autor, considerando encontrarem-se similitudes entre os dois vates, causando certo espanto. E, já adiantando o escopo deste estudo literário comparativo, aludimos ao segundo canto de Pão maligno com miolo de rosas, de Nauro Machado, no qual reluz inegavelmente o brilho do verso milaniano:

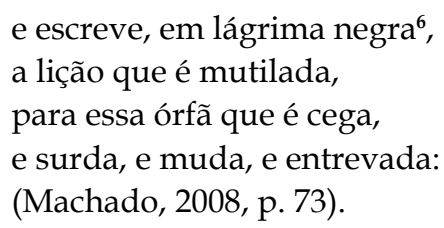

Destarte, propomos um estudo comparativo sobre a presença recorrente de imagens e de signos literários ligados ao sinistro, fantasmagórico e infernal, aos quais, de antemão indicamos o alcance hermenêutico, já circunscrevendo o uso do termo "imaginário do mal". A grande maioria dos críticos e analistas dessas obras, como se verá a seguir, destaca essa característica nas produções literárias estudadas, e não é preciso muito esforço para confirmá-la concretamente na análise direta, que aqui vamos realizar, das obras poéticas dos dois literatos ${ }^{7}$.

Sondando a produção literária do poeta carioca Dante Milano, identificamos que, do conjunto dos 141 poemas que compõem toda a sua obra - estruturada no que Ivan Junqueira chamou de "tripé temático" - percebemos a recorrência persistente destes signos: morte, amor e sonho. Dos dados estatísticos compilados por Junqueira, retirados do vocabulário da obra poética completa de Milano, registram-se 77 referências diretas à palavra "morte", 69 para a palavra "amor", e 58 para a palavra "sonho" Portanto, como se pode deduzir, Milano parece ter elegido a morte como "tema nuclear de toda a sua dolorosa e crispada mentação poética", re-

\footnotetext{
${ }^{6}$ Signo de simultaneidade surpreendente, Lagryma negra é o título do primeiro poema publicado por Dante Milano, em 1920.

${ }^{7}$ O presente texto é um dos resultados da pesquisa que desenvolvemos desde 2005, quando do primeiro estágio de pós-doutorado realizado na UFRJ, com continuação no segundo estágio, realizado em 2009, na UERJ. O livro Museu mefistofélico (Corrêa, 2008) contém parte dos dados levantados nesse processo de investigação, o qual este texto complementa com novos aspectos. Mais informações encontram-se na home page do Grupo de Pesquisas e Estudos Culturais (CRISOL): <www.crisolgpec.com.br>. Nesta oportunidade agradecemos o apoio das agências de financiamento, CNPq (2006) e Fapema (2010).

${ }^{8}$ Não se pode deixar de fazer referência ao fato de a palavra suicídio aparecer também com significante frequência, num total de seis registros, no conjunto das coletâneas que compõem sua obra completa.
} 
velando assim uma "dramática consciência agônica de si mesmo e da existência" (Milano, 2004, p. XXVI).

No caso do poeta maranhense Nauro Machado, vamos ater nossa análise a apenas três cantos de sua vasta obra literária, reunidos sob o título Trindade dantesca (2008). Nesse livro, publicado em conjunto com Litania da velha, de Arlete Nogueira, e o vídeo Infernos, de Frederico Machado, encontramos condensada a mais recente produção literária do poeta maranhense. A Trindade dantesca, nomeando o poema integral, reuniu três cantos publicados em anos diferentes. Assim temos: A rocha e a rosca (2003), Pão maligno com miolo de rosas (2004) e Pátria do exílio (2005). Soma-se a esse conjunto de cantos um poema que serve de epígrafe, intitulado "Canção do (D) exílio", publicado originalmente em 1986, no livro Opus da agonia.

Nossa pesquisa literária comparativa relacionou possíveis simetrias recíprocas do "tripé temático" sugerido por Ivan Junqueira, recolhendo da obra machadiana de 2008 o número de vezes em que os termos "amor, "sonho" e "morte" apareceram no poema Trindade dantesca. Acrescentamos apenas o termo "mal" e seus derivativos, para dar complementação à constelação simbólica e imaginária investigada neste artigo, além de realçar e destacar o vasto vocabulário acessório que é desfilado no decorrer dos três cantos. Assim, no nosso quadro sinóptico e estatístico, encontramos os seguintes números: a) "morte": 97; b) "sonho": 36; c) "amor": 15. Para a palavra "mal", encontramos 24 referências.

Do quadro comparativo revelado destacamos alguns aspectos. Primeiro, é que comparamos números retirados de conjuntos distintos de obras. No caso de Nauro Machado, pesquisamos o livro de poemas Trindade dantesca, em que se enquadra a temática mais ampla do estudo sobre o imaginário do mal, cujos signos do "infernal", "demoníaco" e "mefistofélico", destacam-se sobremaneira, como se verá a seguir. Como já se adiantou, essa obra reúne poemas (cantos) editados isoladamente no decorrer da última década9. No caso de Dante Milano, recolhemos as referências da obra poética integral, isto é, dos 141 poemas publicados.

Ao aproximarmos os dois quadros estatísticos compilados, ficou evidente a presença espantosa do signo "morte" na análise de apenas uma obra de Nauro Machado. Enquanto em toda a poesia de Dante Milano encontramos 77 referências, na Trindade dantesca, encontramos 97! Portanto, repetindo com segurança a sentença analítica proferida para o poeta

\footnotetext{
${ }^{9}$ Todavia vê-se que no conjunto da obra a temática aqui analisada tem vasta dimensão temporal, haja vista o fato de, na vastíssima bibliografia do autor, constarem títulos dedicados à matéria desde os anos de 1970, como Os parreirais de Deus (1975) e Os órgãos apocalípticos (1976), com destaque para A antibiótica nomenclatura do inferno (1977).
} 
Dante Milano, cunhada por Ivan Junqueira, Nauro Machado nos parece do mesmo modo ter elegido a "morte", ao menos nessa obra que analisamos, o "tema nuclear de (...) sua dolorosa e crispada mentação poética", revelando uma "dramática consciência agônica de si mesmo e da existência" (Milano, 2004, p. XXVI). Já os outros dois termos do "tripé temático" ("amor" e "sonho") não adquirem os mesmos valores dos de Dante Milano; contudo, são importantes indicadores das características peculiares de cada literatura. É preciso apontar ainda que a palavra "mal" introduz um elemento singular que não floresce isoladamente. Junto a esse significante, encontramos uma profusão de termos indiretos, associados tanto à morte quanto ao mal. É o que se vê num vocabulário rico com marcas do sinistro, macabro e fúnebre, do mesmo modo que em Dante Milano. São diversas e numerosas as referências diretas a cemitério, funeral, defunto, cadáver, cova, coveiro, túmulo, sepultura, caixão, enterro, e assim por diante, ressonâncias muito presentes do imaginário literário do mal nos dois poetas, que, como veremos, sofreram influências que vêm desde os poetas clássicos até os românticos.

Na tentativa de compreender os possíveis vínculos entre a vida e a obra do poeta carioca Dante Milano, infelizmente ainda desconhecido do grande público, foi preciso um esforço de esclarecimento dos aspectos e das bases de sustentação de sua verdadeira "gnosiologia fantasmagórica", transmutada da poética milaniana e levada à "suprarrealidade" da vida. A palavra "suprarrealidade" não é mencionada gratuitamente, pois se refere a um dos laços que vinculam os conjuntos da análise: "assombros e fabulações surrealistas" que, segundo Ivan Junqueira, caracterizam o seu "fulgurante lirismo visionário". Como se sabe, esse lirismo visionário marcou a obra de outro grande poeta francês pré-surrealista, Arthur Rimbaud (1854-1891), mestre da obra Une saison en l'enfer e poeta que também marcou profundamente a poética de Nauro Machado. Rimbaud sobressai nesse cenário ao lado de Charles Baudelaire (1821-1867), ambos criadores da poesia moderna no Ocidente. Junqueira complementa:

Dante Milano era acostumado à seleta e austera companhia dos antigos e leitor contumaz de Dante Alighieri (de quem verteu modelarmente três cantos do Inferno), Horácio, Virgílio e Leopardi (sobre quem escreveu um memorável estudo), bem como de outros autores italianos do Trecento e do Cinquencento, dos pré-rafaelitas ingleses, de Camões e daqueles que, como Baudelaire e Rimbaud, já antecipavam a poesia moderna na segunda metade do século XIX, Dante Milano formou-se, enquanto modernista, a partir de uma herança acima de tudo classicizante (Milano, 2004, p. XXV). 
Percebemos da mesma maneira, uma vez mais, ressonâncias desse trajeto poético na obra de Nauro Machado. A leitura dos poemas de Dante Milano e de Nauro Machado nos oferece oportunidade excelente para compreendermos os alcances profundos que essa estrutura mítica atingiu entre nós. Nos dois poetas observamos desfilarem figuras do mundo urbano brasileiro em tipos malditos, devassos, velhacos, decrépitos, vagabundos, tresloucados, bêbados - figuras do cotidiano que denunciam, segundo Junqueira, "o fascínio (...) pelas personagens marginais, os deserdados da sociedade e os vagabundos de toda têmpera" (Milano, 2004, p. XXXIV). Somam-se a esse acervo heteróclito diversas imagens e cenas macabras e fúnebres, num verdadeiro baixo-relevo funerário da vida (destaque para o título de um dos poemas que compõem a coletânea chamada Distâncias de Dante Milano).

É importante também enfatizar que, no poeta carioca, numa característica destacada pelo historiador Sérgio Buarque de Holanda, encontramos uma "sistemática predominância do símile sobre a metáfora" (Holanda, 1978, p. 123). Sobressai essa característica estética porque impressiona a atração do poeta pelas imagens cruas, grotescas e bizarras. Tais imagens são homólogas, ou análogas, em sua maioria, ao cenário museológico das coleções do Museu da Magia Negra hospedadas no Museu da Polícia Civil do Rio de Janeiro, o qual o poeta carioca dirigiu e onde trabalhou por muitos anos, até se aposentar ${ }^{10}$. A ausência sistemática do uso da metáfora explica, em parte, a atração e fascínio que o poeta, e escultor bissexto, possivelmente nutria pelas peças e objetos que fazem parte daquelas coleções museológicas, encenando crimes, homicídios, aberrações, monstruosidades, drogas, fetiches, etc. ${ }^{11}$.

Ivan Junqueira escreveu sobre a importância desse "caráter estrutural" da poética de Dante Milano:

No processo analógico operado através do símile não ocorre, como no caso da metáfora, nenhuma substituição de significado destinada a sugerir uma semelhança que ai apenas subentende. Ora, a linguagem crua e transparente do autor jamais poderia absolver o

\footnotetext{
${ }^{10}$ Desse modo, acredita-se que - diferentemente da visão modernista de Mário de Andrade, Arthur Ramos e Gilberto Freyre, entre outros - Dante Milano "via" nesse conjunto de peças e objetos expressões simbólicas do mundo do mal e satânico (mefistofélico) que povoava sua imaginação poética, sob influência de Dante Alighieri e Charles Baudelaire. Os outros autores citados, ao contrário, procuravam integrar a religiosidade negra e africana na cultura brasileira mestiça. Deve-se recordar, por exemplo, a descrição que há em Macunaíma ([1928]1979) do terreiro da Tia Ciata, muito frequentado por boêmios, artistas e intelectuais, na antiga Praça Onze, centro do Rio de Janeiro.

${ }^{11}$ Para mais detalhes sobre o Museu da Magia Negra do Rio de Janeiro, ver o livro, escrito pelo autor deste artigo, Museu mefistofélico (Corrêa, 2009).
} 
barroquismo sensualístico em que, não raro, se resume o jogo de luz e sombra imposto pela metáfora. Assim, a comparação direta e frontal proporcionada pelo símile atenderia mais às exigências do pensamento, enquanto o processo elíptico de substituição da metáfora satisfaria, com maior pertinência, às instâncias da emoção. Vê-se, portanto, que esse predomínio do símile é antes de caráter estrutural do que propriamente formal (Milano, 2004, p. XLIII).

Apesar de características singulares, devido à trajetória biográfica distinta, encontramos a mesma fixação pelas "imagens cruas, grotescas e bizarras", onipresentes no texto Trindade dantesca, de Nauro Machado. Destarte, essa "sistemática predominância do símile sobre a metáfora" foi recolhida pelo poeta nas ruas antigas e coloniais de São Luís do Maranhão, surgindo de modo epifânico nos seus cantos. Uma São Luís que emerge do poema:
terra má, flor do antraz,
mãe madrasta e meretriz,
dando à minha alma sem paz
o que eu tenho e nunca quis,
no corpo que ainda em mim jaz
pisando o chão de São Luís!
(Machado, 2008, p. 107).

É de São Luís, seu torrão natal (homeland), torrão maranhense, que o poeta Nauro Machado ergue seus cantos da Trindade dantesca: seu torrão infernal ${ }^{12}$.

Ao tecer o trabalho de comparação entre aspectos da poética de Nauro Machado e da obra literária de Dante Milano, promovemos uma breve pesquisa nos substratos do inconsciente cultural, e a partir de uma culturanálise de suas produções literárias, encontramos continentes profundos de onde parecem emanar as imagens predominantes em suas poéticas. Assim, por meio de um tipo de arqueologia, realizamos uma espécie de

\footnotetext{
12 Utilizamos o termo torrão no sentido de torrão natal (homeland), terra natal, empregado pelo geógrafo maranhense Raimundo Lopes, que aos 17 anos de idade publicou livro famoso no Maranhão, O torrão maranhense. Essa obra hoje compõe publicação reeditada conhecida como Uma região tropical (Lopes, 1970). A expressão adquiriu grande repercussão no imaginário regional, surgindo recorrentemente em toadas de bumba-boi e em diversas canções e poemas populares e eruditos. Utilizamos a expressão no título desse artigo, já que - apesar das distinções na forma de se vincular a terra natal, peculiares em Nauro Machado e Dante Milano - os dois poetas nutriam forte afeto pelo lugar de nascimento e vida, respectivamente São Luís e Rio de Janeiro. Em breve, vamos desenvolver estudos sobre possíveis paralelos literários entre o torrão natal (homeland) dos poetas brasileiros e a wasteland (terra baldia) do poeta T. S. Eliot (1888-1965).
} 
escavação sobre as similitudes e homologias temáticas que surgem da leitura das duas poéticas em tela, percorrendo um trajeto histórico-cultural necessário, a fim de buscar as origens e as bases de sustentação da estrutura de sentimentos constituinte do imaginário e do simbolismo do mal, salientes nas literaturas de Dante Milano e de Nauro Machado.

\section{Imagens dialéticas}

A dialética expressa na polarização entre o Céu e o Inferno, o Bem e o Mal, o Paraíso e as Trevas, tem uma presença muito marcante nas obras dos poetas carioca e maranhense que agora analisamos. Essa dialética de imagens possui um lastro no imaginário, que nos remete a estruturas muito profundas, tanto na história quanto na cultura ${ }^{13}$. Todavia, é preciso adiantar que, ao tratar essa polarização como uma configuração mitológica, não nos restringiremos às suas figurações na modernidade, ou ao mundo ocidental. Pelo contrário, é preciso partir do ponto de vista de que essa polarização é histórica e estruturalmente muito antiga. Trata-se, na verdade, da configuração de uma mentalidade arquetípica que remete tanto à Antiguidade Clássica quanto aos primórdios da civilização judaico-cristã e, também, à tradição árabe.

No entanto, não é objetivo deste trabalho realizar uma vasta arqueologia dessa dialética tão antiga; nosso intuito é bem mais modesto. Pretendemos apenas remontar à história e à estrutura dessa mentalidade ao contexto da colonização europeia, ou melhor, ibérica, na formação das nações da América do Sul, especialmente do Brasil. Apesar de ter em mente que essa estrutura tem raízes históricas profundas, desejamos aqui fundamentar o argumento apresentado no período histórico, cujo marco é designado como Descoberta da América.

\section{Paraíso terreal}

O historiador paulista Sérgio Buarque de Holanda, no seu livro clássico Visão do Paraíso (1959), enfatizava que, ao contrário dos lusitanos, pouco

\footnotetext{
${ }^{13}$ Nesse sentido, as imagens dialéticas que são invocadas no texto estão sob a influência das análises benjaminianas (Benjamin, 1984), mas especialmente do modo como são recuperadas por Michael Taussig. Benjamin advogou uma espécie de técnica surrealista denominada "imagem dialética”, noção obscura à qual Theodor Adorno se referia como "quebra-cabeças pictóricos que chocam devido à sua forma enigmática e, através dela, desencadeiam o pensamento”. A “imagem dialética” é em si uma montagem que, ao mesmo tempo, capta as já mencionadas conexões entre dessemelhantes e aquilo que, a partir desse procedimento, é captado (Taussig, 1993, p. 347).
} 
afeitos à fantasia, foram os espanhóis que mergulharam profundamente no maravilhoso das lendas e mitos edênicos na aventura da travessia do Oceano Atlântico. Contudo, observa-se que, na configuração histórica dos mitos de colonização luso-brasileira, analisados nessa obra paradigmática, Sérgio Buarque de Holanda destaca, numa passagem sintética do capítulo "Um mito luso-brasileiro", a particularidade mitológica lusitana:

É sempre curioso notar como o São Tomé americano que, para os colonos e missionários do Brasil, não passa, se tanto, de um mito vagamente propedêutico, se vai enriquecer e ganhar maior lustre à medida que a notícia de suas prédicas se expande para oeste, rumo às possessões de Castela. Sendo, como é, de fato o único mito da conquista cuja procedência luso-brasileira parece bem assente, essa circunstância é o bastante, sem dúvida, para dar uma noção da mentalidade que dirigiu cada um dos dois povos ibéricos em sua obra colonizadora (Holanda, 2000, p. 156-7).

O interesse aqui é sublinhar a expressão "noção da mentalidade que dirigiu cada um dos povos ibéricos". Sérgio Buarque de Holanda, nessa obra, antecipa a história das mentalidades, que se desenvolveu na França nos anos 1960. A partir do diálogo transversal com disciplinas diversas, como a antropologia, a sociologia, a filosofia e a literatura, o historiador abre novos caminhos para os estudos do imaginário da época dos descobrimentos marítimos. Escolhe como objeto de análise investigar a força da sedução pela poderosa metáfora do Éden. Para o eminente historiador, esse aspecto é a marca da distinção entre a colonização da América Inglesa e a da América Latina. Enquanto, na primeira, procura-se realizar, na colônia, o "puro ideal evangélico", na segunda, move a "esperança de ingressar num Paraíso coberto de riquezas e de bem-aventurança divina como dádiva natural e gratuita" (Holanda, 2000, p. 445).

Na profícua descrição da geografia fantástica do Brasil, o tema, explorado repetidamente, era o do país como o Jardim do Mundo, o Paraíso Terreal, onde se concretizaria a crença no mundo intangível, incorpóreo, perdido no começo dos tempos. A importância dos mitos edênicos, no imaginário social da colonização da América, foi inegável e constitui a configuração de um paradigma comum entre espanhóis e portugueses. Todavia, não havia um imaginário europeu homogêneo, já que os portugueses apresentavam mais pragmatismo. Percebia-se também uma mentalidade distinta entre os italianos, que possuíam um tipo de pessimismo ancestral:

Não é por acaso se justamente entre italianos, mais familiarizados, então, do que outros povos, com especulações de tal porte, tenda a 
desprender-se, aqui e ali, de um pessimismo adverso à tranqüilidade de ânimo que propugnam os humanistas, a esperança e procura de alguma solução terrena. Nem falta quem, como um Maquiavel, chegue a aceitar, sem ilusões, o mundo como é, imaginando mesmo uma ordem civil edificada sobre esse material imprestável que são os homens, de sorte que a velha ruindade venha a sujeitar-se a novas leis que a neutralizem, num verdadeiro equilíbrio de egoísmos, e que do próprio mal possa brotar o bem, com o soldar-se dos indivíduos corruptos no Estado forte (Holanda, 2000, p. 232).

Neste momento, devemos considerar que o carioca Dante Milano tem origem familiar italiana. O lado sinistro, fantasmagórico e desértico da poética de Dante Milano parece ter antecedentes muito profundos no inconsciente da diáspora dos italianos ${ }^{14}$. Porém, sobre as supostas explicações e razões "étnicas" na distinção do caráter de espanhóis, portugueses e italianos, etc., Sérgio Buarque de Holanda alerta:

Alguns seriam tentados a filiar essa novidade a insondáveis razões étnicas, que pairassem acima de todas as contingências. É um modo, este, de simplificar, não de esclarecer o problema. Poderia lembrar-se também que a tradição e, porventura, certa vocação imperial, não seria estranha ao caráter dos espanhóis, e ainda aqui andaríamos perto daquelas misteriosas razões que pretendem dispensar explicação e inquérito. É exato que neste caso particular, elas têm em seu favor certos fundamentos históricos pelo menos impressionantes (Holanda, 2000, p. 385).

É o caso exato da poética de Dante Milano, que, em sua mitologia pessoal, cultivava com muita serenidade a tradição dos clássicos italianos, começando por Dante Alighieri. Juntamos agora peças de um quebra-cabeça que se articulam de forma bastante plausível - não parece que se força a comparação, ou que se força a realidade, ou os fatos, à camisa-de-força da teoria. Dante Milano cultivou uma herança cultural que reflete o imaginário social e a mentalidade dos migrantes italianos, de acordo com a constatação do historiador Sérgio Buarque, em uma análise que combina

\footnotetext{
${ }^{14}$ É preciso que se anote que Dante Milano, sobre ele mesmo, disse: "Não tenho uma idéia exata sobre mim mesmo. A autocrítica me é muito difícil porque eu não me contemplo. Concordo com os críticos. Paulo Mendes Campos foi muito penetrante, só não estou de acordo com a afirmação de que sou sinistro, sempre me achei uma doçura; a análise de Franklin de Oliveira me parece muito certa, ele conhece bem as influências que sofri; o Sérgio Buarque de Holanda me deixa em suspenso, porque o seu artigo diz que poderia escrever mais sobre mim, e quanto a Schmidt e Bandeira, é uma explosão da expressão da amizade" (Neves, 1996, p. 165).
} 
e se encaixa perfeitamente com as hipóteses aqui levantadas. Isso explica, ao menos em parte, que, entre os cinco maiores poetas do Modernismo brasileiro, Dante Milano tenha-se mantido como um tipo singular, um outsider, um forasteiro ${ }^{15}$ e um típico homem marginal - no sentido dado ao termo pela sociologia norte-americana da Escola de Chicago ${ }^{16}$.

Tal singularidade, produzida pelos efeitos de uma herança cultural particular, efetivamente engendrou um tipo específico de performance poética, literária e cultural, que pode servir de explicação para a musealização inusitada e curiosa da Coleção de Magia Negra da Polícia Civil do Rio de Janeiro. Não explica apenas a criação desse acervo, mas também, ao menos em parte, as razões para o pedido de tombamento dessa coleção heteróclita - que contrastava completamente com a vertente arquitetônica dominante, em torno da figura de Lúcio Costa, e também com a mentalidade dos modernistas como Arthur Ramos, Mário de Andrade e outros, que lutavam em suas vidas pela dessatanização e desdiabolização da expressão cultural dos negros, ou afrodescendentes.

No caso de Nauro Machado, em São Luís, consideramos alguns títulos de sua vasta bibliografia como indicadores da sua longa e recorrente vinculação ao tema metafísico do Céu e do Inferno, como em Necessidade do divino (1967), Os parreirais de Deus (1975), Os órgãos apocalípticos (1976), A antibiótica nomenclatura do Inferno (1977), além dos poemas já citados. Podemos dizer, sem hesitações, que aspectos e particularidades literárias marcantes o aproximam muito de Dante Milano. Não há quem não identifique em Nauro Machado uma poética nuclearmente metafísica, como no poeta carioca, "sondando angústias, inquietações e dilacerações do eu mais profundo do ser humano", como escreveu Hildeberto Barbosa Filho - como se estivesse descrevendo Dante Milano:

Poucos poetas - talvez um Baudelaire, um Antero de Quental, um Augusto dos Anjos - têm, como esse solitário maranhense, enfrentado a tarefa árdua e encantatória de expressar, mas o fazendo sob o regime de uma consciência criadora face às possibilidades do verbo - verbo que é fala, pensamento, imagem e melodia - os ângulos escusos, os obscuros abismos, as cartilagens doloridas e inescrutáveis da estrutura humana (Fortuna Crítica) (Machado, 2012, p. 430).

\footnotetext{
${ }^{15}$ Entrevista de Dante Milano a Denira Rozário: "Para mim não existe brasileirismo em arte nenhuma. Não há pintura brasileira, poesia brasileira. Poesia ou é poesia ou não é poesia. Eu não me considero um poeta brasileiro. Me considero um poeta, em qualquer língua. E se vou à imprensa de língua portuguesa, sou um poeta português” (Neves, 1996, p. 115).

${ }^{16}$ Há um paralelo interessante também que pode ser feito com o termo "nacional-estrangeiro", cunhado por Sérgio Miceli (2003).
} 
Encontramos muitos pontos de contato e comunicação entre os dois espíritos poéticos fascinados pela temática metafísica, emoldurados pela tela ampla do maior de todos os dramas, no vertiginoso labirinto dos destinos entre a Luz e as Trevas, entre o Paraíso e o Inferno. Tanto em Nauro Machado quanto em Dante Milano, seguindo a longa trilha da Antiguidade à Modernidade - de Dante Alighieri, passando por Charles Baudelaire - percebemos a continuidade mítica persistente da temática da morte e do obscuro, do tenebroso e do escuso. Essa polarização dramática atravessa as duas obras literárias, elaborando símbolos e signos oferecidos pela cultura. É na história cultural que vamos encontrar as bases estruturais em que os poetas vão sustentar seu trajeto lírico. E, como ilustração dos contrastes na configuração dos imaginários desse drama comum, fundados desde a descoberta da América, podemos pontuar alguns exemplos de narrativas sobre a visão do paraíso no Brasil, destacando agora as Cartas do Brasil, do português Pe. Manuel da Nóbrega, escritas em 1549, a respeito de Salvador da Bahia:

É muito sã e de bons ares, de tal maneira que, com ser a gente muita e ter muito trabalho, e haver mudado os mantimentos com que se criaram, adoecem muito poucos, e esses que adoecem logo saram. É terra muito fresca, de inverno temperado, e o calor de verão não se sente muito. Tem muitas frutas e de diversas maneiras, e muito boas, e que têm pouca inveja às de Portugal. Os montes parecem formosos jardins e hortas, e certamente em nunca vi tapeçaria de Flandres tão formosa, nos quais andam animais de muitas diversas maneiras, dos quais Plínio nem escreveu nem soube. Tem muitas ervas de diverso olor e muito diferentes das de Espanha, e certamente bem resplandece a grandeza, formosura e saber do Criador em tantas, tão diversas e formosas criaturas (Nóbrega apud Holanda, 2000, p. 290).

Têm-se, por fim, os testemunhos do Mundo sem mal, no livro Diálogos das grandezas, de Brandônio:

porque toda gente, de qualquer nação que seja, prevalece nele com saúde perfeita, e os que vêm doentes cobram melhoria em breve tempo. E a razão é o serem estas terras do Brasil mais sadias e de melhor temperamento que todas as demais (Holanda, 2000, p. 317).

Como corolário dessa mentalidade dividida entre polos radicais mentalidade tão poderosa a ponto de deixar marcas profundas nos poetas aqui estudados - difundiu-se por séculos a ideia de que a natureza 
brasileira em especial é maravilhosa, exuberante e fantástica - verdadeiro Paraíso Tropical; porém, em contrapartida, o mal existe, e persiste - e tem habitado nas profundezas dos corações e mentes dos homens e mulheres que povoam a América, abaixo da linha do Equador.

\section{Terra infernalis}

Entre tantas exaltações e apologias das maravilhas dos trópicos, verse-á que não se elaboraram apenas quimeras no imaginário europeu sobre a América; forjaram-se também pesadelos de infernos e purgatórios. Nos estudos que enfocam o outro lado da visão do paraíso, encontram-se alguns traços significativos desse outro imaginário, o outro lado do espelho refletido. Os textos O Diabo e a Terra de Santa Cruz: feitiçaria e religiosidade popular no Brasil Colonial, de Laura de Mello e Souza (2005), e o Diabo nos porões das caravelas: mentalidades, colonialismo e reflexos da constituição da religiosidade brasileira nos séculos XVI e XVII, de Iza Gomes da Cunha Chain (2003), nos oferecem rico material sobre o tema. Laura de Mello e Souza apruma nosso foco:
A infernalização da colônia e sua inserção no conjunto dos mi- tos edêmicos elaborados pelos europeus caminharam juntas. Céu e Inferno se alternavam no horizonte do colonizador, passando paulatinamente a integrar também o universo dos colonos e dan- do ainda espaço para que, entre eles, se imiscuísse o Purgatório. Durante todo o processo de colonização, desenvolveu-se pois uma justificação ideológica ancorada na Fé e na sua negação, utilizando e reelaborando as imagens do Céu, do Inferno e do Purgatório. (...) Céu, Inferno e Purgatório alternavam-se portanto na montagem do Sistema Colonial" (2005, p. 372).

Parece não ser necessário frisar que, para o interesse que se tem, essa estrutura polar (paraíso e inferno), apesar de mutações e metamorfoses na narrativa moderna, ainda vigora e "dirige" o imaginário dos povos que habitam e constroem suas vidas nas Américas, especialmente no Brasil contemporâneo. Poder-se-ia fazer referência ainda às muitas variantes mitológicas desse núcleo comum - que em muitos aspectos preserva conteúdos compartilhados com os povos fundadores ibero-americanos.

Uma das variantes mais recentes do mito do paraíso está no hit tropicalista dos anos de 1970, composto por Jorge Ben Jor, "País tropical". No outro polo, em que se enfatiza o lado infernal da vida nos trópicos, observa-se a proliferação de narrativas sobre $O$ mal à brasileira, analisadas nesse 
interessante livro organizado por Patrícia Birman (1997), assim como no escavar mais profundo dos textos analíticos de Joel Birman, presentes no livro Os cadernos sobre o mal (2009).

O debate sobre o Brasil do Paraíso e do Inferno, como se vê, vem de longa data e atravessa séculos. Nossos argumentos se baseiam nessa estrutura de longa duração, para poder compor um quadro de referência interpretativo que possa oferecer uma compreensão mais fundamentada sobre o imaginário do mal que emerge nas poéticas estudadas. Para tal procurou-se investigar o mito que poderia estar na raiz, na base, ou melhor, na "noção da mentalidade que dirigiu" - segundo expressão de Sérgio Buarque - o inconsciente cultural e literário dos dois poetas em foco.

No intuito de ilustrar a configuração do polo oposto à Visão do Paraíso, encontra-se na obra de Iza Chain O Diabo nos porões das caravelas uma visão complementar àquela que o historiador Sérgio Buarque ofereceu, no final da década de 1950. Nesse livro, Iza Chain, que também segue as orientações teóricas da história das mentalidades, descreve o imaginário da descoberta, enfocando especialmente o explorador português. A autora, a partir do levantamento de dados em documentos, narrativas e cartas, encontrou diversos depoimentos que comprovariam que, logo após ter vigorado a crença de que as viagens marítimas poderiam conduzir ao paraíso terreal, começaram a proliferar diversas narrativas em contrário, afirmando que ao sul do Equador, na verdade, habitavam os seres do baixo mundo, e que, no Brasil, particularmente, vivia o Artífice do diabólico: a Terra Brasil infernalis.

Na configuração imaginária da mentalidade lusitana da época dos descobrimentos marítimos, encontram-se análises de diversos autores que contribuem para confirmar essas versões históricas, especialmente a de Michel de Certeau (1970), que:

não hesitou em apontar o século XVI e os primeiros sessenta anos do século XVII como os períodos mais satânicos da Europa Cristã. Foi nesse contexto, envolta em uma densa aura de satanismo, que a Cristandade europeia aportou em solo americano, pronta a detectar e combater rastros da malignidade diabólica para além do Atlântico singrado (Chain, 2003, p. 85)

A historiadora portuguesa Maria Benedita Araújo, na obra Magia, demónio e força mágica na tradição portuguesa (1994), também destacou, nos seus estudos, a significativa presença de Satanás no imaginário da sociedade lusitana na época da passagem para a Idade Moderna. 
Iza Chain lembra, também, uma questão interessante relacionada à escolha definitiva do nome do país. Como se sabe, este surge inicialmente como Terra de Santa Cruz, mas em seguida acaba fixando-se o topônimo Brasil. Sobre essa mudança o Frade Vicente de Salvador afirmara que o Diabo "perdera progressivamente o controle sobre a Europa e viera se instalar vitorioso na outra banda da Terra, mais especialmente no Brasil".

Para o religioso, as artimanhas diabólicas chegavam mesmo a influenciar o nome e a designação de Brasil, que passavam a denominar a colônia, lembrando as brasas infernais, avermelhadas (Chain, 2003, p. 88-99).

No embate entre Deus e o Diabo na terra do sol ${ }^{17}$ - parodiando o título do filme genial do cineasta baiano Glauber Rocha (1939-1981) -, os portugueses tornavam-se "etnodemonólogos" por força das circunstâncias, travando uma luta sem fim contra Satã, o Diabo, e as forças do mal, que poderiam tomar as terras recém-descobertas, da cristandade restaurada, após as guerras de 700 anos contra os mouros. Nesse combate emergiram representações estereotipadas pautadas pelo imaginário fantasmagórico e teratológico lusitano: “(A) terra brasileira ia, dessa forma, sendo integrada ao imaginário da sociedade portuguesa, recebendo, dentro de esquemas eurocêntricos, classificações e valores ditados pelas mentalidades daquela sociedade" (Chain, 2003, p. 90). Essa guerra civilizatória culmina com as Visitações do Tribunal do Santo Ofício em 1543 e 1591.

Captando e promovendo o cruzamento entre as próprias formulações eruditas e as vivências religiosas ao nível popular, o procedimento inquisitorial contribuiu para que o estereótipo da feiticeira e do pacto diabólico se perpetuasse em solo brasileiro, agindo basicamente da mesma forma que na Metrópole, ou seja, criando canais para que se multiplicassem as delações através de editais afixados nas Igrejas, os quais estabeleciam as culpas sujeitas à alçada do Santo Tribunal e as possíveis benesses concedidas aos delatores (Chain, 2003, p. 92-93).

Toma-se a liberdade de observar que essa configuração histórica, apesar de sofrer transformações no decorrer dos séculos, mantém-se indelével e atual. Constata-se que essa configuração "se perpetuou em solo brasileiro", principalmente quando se têm em conta as práticas desenvolvidas

\footnotetext{
17 Filme em película 35 mm, ficção, longa-metragem, preto e branco. Copacabana Filmes. Rio de Janeiro, 1964. Essa película cinematográfica é especialmente apropriada à compreensão da construção narrativa elaborada nesta parte do nosso artigo.
} 
pelas seitas cristãs pentecostais contemporâneas, que reproduzem a mesma forma de luta religiosa de séculos atrás, utilizando os mesmos estereótipos e representações históricas contra os "barbarismos" imputados aos "diferentes, pagãos, gentios, infiéis, idólatras ou hereges" - todas características consideradas diabólicas, exorcizadas em seus cultos contemporâneos. Convém se lembrar nesse particular de Vagner Gonçalves da Silva (2007), que denuncia os extremos de um conflito de longa duração, com roupagens novas. Em outro livro é revelada também a lógica subjacente a esses embates religiosos e políticos; trata-se do já referido $O$ mal à brasilei$r a$, organizado por Patrícia Birman (1997) ${ }^{18}$.

Seguindo essa mesma trilha e tratando mais especificamente dos ecos e heranças dessa luta, ao investigar as vicissitudes de um longo processo que se alastra desde os Tribunais do Santo Ofício do século XVI até a sociedade brasileira republicana e positivista do início do século XX - como repercussões difusas num ciclo histórico que não parece findar - , temos as pesquisas sobre os processos de acusação de bruxaria, magia e feitiçaria reunidas por Yvonne Maggie no seu livro O medo do feitiço (1993). Essa obra coloca em evidência aspectos ainda obscuros da lógica cultural e civilizacional que estrutura tais ações e embates no campo religioso brasileiro. Nas pesquisas levantadas são identificados os mesmos repertórios de "adivinhações, curas mágicas, benzeduras, mezinhas, pactos diabólicos, práticas ocultistas, antropofagias, exorcismos praticados pela população laica, conjuntos demoníacos, pessoas enfeitiçadas e malefícios que infestam a colônia brasileira" (Sousa, 1986, p. 157). Pode-se afirmar que tal enfrentamento ainda persiste virulento, e se reproduz até hoje, num sem número de casos espalhados pelo país e pelo continente (Silva, 2007).

Retornando ao domínio da literatura e da poesia, sobre o qual nos movimentamos mais especificamente neste texto, e considerando particularmente a obra Trindade dantesca, de Nauro Machado - porém, recuperando outras referências na vasta constelação de textos e obras em que o poeta maranhense desenvolveu o tema do infernal, assim como na obra do poeta carioca Dante Milano -, nos reaproximamos, com novo olhar, desse conjunto imaginário e simbólico de lastro profundo em nossa cultura. É por

\footnotetext{
${ }^{18}$ Nas festas de final de ano de 2005, em Salvador da Bahia, grupos evangélicos espalharam diversos panfletos que foram colados em telefones públicos (“orelhões”) nos quais atacavam as manifestações religiosas afro-brasileiras, identificando nelas expressões diabólicas e demoníacas. Após reportagem da Rede Bandeirantes, o Ministério Público pretende encaminhar ação pública e investigação policial, qualificando como crime de intolerância religiosa, já que os ataques se direcionavam aos símbolos tradicionais da cultura afro-brasileira como São Jorge, Senhor do Bonfim e Iemanjá.
} 
essa vereda interpretativa que vamos alinhavar as palavras finais deste texto exploratório.

\section{Literatura e o mal}

Após essas considerações, parece justo colocar que o conjunto da obra poética e literária de Dante Milano e alguns aspectos aqui destacados da obra de Nauro Machado podem ser analisados como expressões simbólicas de um imaginário social sobre o mal, compartilhado transversalmente. Parece-nos que essas expressões artísticas e literárias representam com propriedade a forte presença que a herança cultural e imaginária europeia ${ }^{19}$ tem na nossa formação cultural e artística, com ênfase na tradição romântica do século XIX, na qual emergem fulgurantes a obra de W. Goethe Fausto e Charles Baudelaire ${ }^{20}$, de As flores do mal, como referências diretas. Essa herança cultural e imaginária foi analisada com muita propriedade na obra clássica de Georges Bataille, A literatura e o mal (1957), na qual encontramos estudos aprofundados desse tema em autores como Emily Brontë, Michelet, William Blake, Sade, Proust, Kafka e Genet. Entretanto, como vimos, essa tradição romântica tem camadas profundas, nos conduzindo até Dante Alighieri, presente nominalmente nas obras dos poetas aqui estudados: em Dante Milano, com traduções de vários dos cantos da Divina comédia, e em Nauro Machado, na própria titulação da obra em destaque, Trindade dantesca.

Além disso, apontamos para o fato de a palavra "inferno" aparecer 20 vezes no corpo dos três poemas-cantos de Nauro Machado, do qual podemos analisar outro aspecto importante. Enquanto em Dante Milano não encontramos referências locais, ou regionais, de uma paisagem coloquial que servisse como cenário para o enquadramento visual do seu inferno

\footnotetext{
${ }^{19}$ Cabe lembrar que em nosso país a crença na magia é dominante e difundida por todas as classes sociais, como se constata no livro Medo do feitiço (Maggie, 1993).

${ }^{20}$ No caso específico de C. Baudelaire, digno de nota é o seu famoso e cultuado "satanismo", associado ao "vampirismo". No texto escrito por Jamil Haddad como introdução à tradução da obra As flores do mal, de 1958, encontram-se elementos que testemunham a difusão do fenômeno do satanismo no Brasil: "Esses dados sobre o satanismo brasileiro estão sendo tirados de tese nossa (O Romantismo Brasileiro e as Sociedades Secretas do Tempo, São Paulo, 1945), em que pudemos demonstrar as relações estreitas do Romantismo com o fenômeno, unanimemente difuso pelo Brasil do tempo, da maçonaria. Pudemos nela demonstrar o caráter maçônico de Álvares de Azevedo como as estreitas ligações que se podem lobrigar entre satanismo literário e satanismo maçônico. Um livro que citamos nesta tese - Le Diable au XIXème siècle (1892), de Dr. Bataille (pseudônimo de Léo Taxil [18541907]) - dá-nos informações sobre as ramificações brasileiras da maçonaria luciferiana. Estas abrangeriam: a) Província triangular do Rio de Janeiro; e, b) Província triangular da Bahia. A Loja do Rio era a Loja-Mãe e chamava-se ‘Lótus do Brasil’” (Haddad, 1981, p. 29).
} 
- deduzindo-se que se trata de um inferno subjetivo, existencial, à la JeanPaul Sartre, no célebre enunciado "o inferno são os outros" -, em Nauro Machado, ao contrário, encontramos um cenário referente e explícito: a cidade de São Luís, "terra que é mãe da peste" (Machado, 2008, p. 119). Assim, se podem recolher vários versos, especialmente no terceiro canto, "Pátria do exílio", em que a urbe ludovicense é descrita de modo dantesco e vertiginosamente infernal; como se vê nesses versos:

Terra a que os meus olhos dão

uma infernal forma imensa,

abrindo-se nesse chão

de putrescível presença,

para os olhos que verão

como quem cego vê e pensa.

Terra onde sempre vivi,

tremendo de noite e de dia,

desde que de dois nasci

para quem só comigo ia,

com quem depois eu vi

ser a tua companhia.

(Machado, 2008, p. 119).

Portanto, podemos afirmar, dos dois poetas analisados emerge um mundo encoberto teimando em ser ocultado sob as retóricas dos bemaventurados e contentes, embalados pelas fantasias, e ideologias, ufanistas de um tropicalismo cínico e persistente. Sob a força dessas duas literaturas poderosas vemos balançar as representações superficiais de uma apologia frouxa, amedrontada e primária. Tanto em Dante Milano como em Nauro Machado descemos bem ao fundo das entranhas de um mundo que não se sustenta sem dores, angústias, horrores e malefícios. São poéticas necessárias que, para além da morbidez acusatória, lançada por sóbrios bem pensantes, e fracos d'alma, nos oferecem luzes penetrantes para atravessar as trevas de uma existência cada vez mais desértica, em tempos demasiadamente conformistas ${ }^{21}$. Destarte, recuperamos a força de versos que dialogam sobrevindos de um silêncio que é mais verdadeiro porque o outro fala por linhas invertidas, uma mensagem trocada, como no belo trecho do poema "Noite":

${ }^{21}$ No sentido contrário ao movimento de se ocultar a dimensão tenebrosa da vida, a hybris tão decantada pelos poetas em tela, encontramos o filme curta-metragem produzido pelo filho de Nauro Machado, Frederico Machado, Infernos (2006). 
As estrelas não são fictícias, são existentes, Mas parecem fictícias...

Todos os sonhos são verdadeiros,

Mas parecem mover-se num plano irreal.

É de mim que nasce o mal,

Todas as coisas são puras.

Sou como um morto andando à toa.

Oh, esse pensamento

Não vem de mim, vem do alto.

Tive de pensá-lo porque se fez presente

Como o abismo ao suicida.

Desejo transcendê-lo

E transformar o mal imaginário

Num bem presente e invisível

(Milano, 2004, p. 49).

Dos versos de Nauro Machado, recolhidos do terceiro canto, "Pátria do exílio", do poema Trindade dantesca, encontramos os ecos musicais de um mesmo mal-estar existencial:

Partir sem leis e regras,

como um pus que é musical

sabendo o amor que desregra

as lisuras do ideal,

murcha ideia a ser das regras

do útero - este eterno mal.

(Machado, 2008, p. 132).

Os elos interpretativos do longo processo cultural e literário aqui entrelaçados e vasculhados, descritos mais acima, foram construídos a partir da análise de aspectos relevantes das vidas e das obras dos dois poetas. Destaca-se dessas aproximações temáticas alinhavadas transversalmente o tema de estudo sobre o imaginário do mal, em análises que contaram com diversos dados e documentos, recolhidos em pesquisas que desenvolvemos desde 2001. Nesse trajeto interpretativo buscamos compreender a semiotização literária e poética da visão sobre o mal na sociedade brasileira. Por meio da literatura e da poesia de Dante Milano e de Nauro Machado, 
buscamos uma visada no "olhar sobre o mal", método que não esgotou a riqueza do material ainda a ser analisado, nem a abrangência dos problemas dos quais só podemos nos aproximar, até o momento. Assim, é preciso afirmar que, ao escolhermos o caminho do estudo de aspectos das obras e das vidas dos poetas em foco, não deixamos de considerar o que Maurice Merleau-Ponty escreveu sobre "A dúvida de Cézanne", em citação aparentemente paradoxal:

Pode-se pois ao mesmo tempo dizer que a vida de um autor nada nos revela e que, se soubéssemos sondá-la, nela tudo encontraríamos, já que se abre em sua obra (1984, p. 125-6).

Sob essa perspectiva tentamos encontrar na sua poesia e literatura os elementos interpretativos que "se abrem em suas obras" com o objetivo de fazer movimentar a nossa máquina interpretativa. Todavia, muitas dificuldades se apresentaram quase intransponíveis, entre elas as idiossincrasias e circunstâncias do humano em cada artista, como é o caso do silêncio cultivado por Dante Milano, fruto de uma contumaz recusa em se "abrir" publicamente, confirmada em vários depoimentos e entrevistas que realizamos com conhecidos, familiares e amigos do poeta. De outro lado, temos as dificuldades em relação aos problemas de saúde de Nauro Machado, impossibilitando uma entrevista mais recente, sobre o tema em destaque. Muito embora os aspectos biográficos não sejam radicalmente fundamentais, também não consideramos, como os adeptos do New Criticism, que o texto literário prescinda da vida e da fala do poeta, pairando autônomo e desvinculado da existência concreta do escritor e do artista $^{22}$. Como constatou Merleau-Ponty: "É certo que a vida não explica a obra, porém certo é também que se comunicam" (1984, p. 122).

\section{Referências}

ANDRADE, Mário de (1979). Macunaíma. São Paulo: Martins. ARAÚJO, Maria Benedita (1994). Magia, demónio e força mágica na tradição portuguesa: séculos XVI e XVII. Lisboa: Cosmos.

BATAILLE, Georges (1989). A literatura e o mal. Porto Alegre: LPM.

BAUDELAIRE, Charles (1981). As flores do mal. São Paulo: Max Limonad.

BENJAMIN, Walter (1984). Origem do drama barroco alemão. São Paulo: Brasiliense.

\footnotetext{
22 Como Sérgio Buarque de Holanda, também nos afastamos de "alguns doutrinadores modernos, muito agarrados ao que chamam supersticiosamente o “texto”” (Holanda, 1978, p. 122).
} 
(1989). Charles Baudelaire: um lírico no auge do capitalismo. São Paulo: Brasiliense.

BIRMAN, Patrícia (org.) (1997). O mal à brasileira. Rio de Janeiro: Editora da UERJ.

BIRMAN, Joel (2009). Cadernos sobre o mal. Rio de Janeiro: Civilização Brasileira. CERTEAU, Michel de (1970). La possession de Loudun. Paris: Gallimard-Julliard. CHAIN, Iza Gomes da Cunha (2003). O diabo nos porões das caravelas: mentalidades, colonialismo e reflexos da constituição da religiosidade brasileira nos séculos XVI e XVII. Juiz de Fora: Ed. UFJF; Campinas: Pontes.

CORRÊA, Alexandre Fernandes (2009). Museu mefistofélico. São Luís: EDUFMA.

HADDAD, Jamil (1981). "Introdução”. In: BAUDELAIRE, Charles. As flores do mal. São Paulo: Max Limonad.

HOLANDA, Sérgio Buarque de (1978). Cobra de vidro. São Paulo: Perspectiva. (2000). Visão do Paraíso. São Paulo: Brasiliense.

LOPES, Raimundo (1970). Uma região tropical. Rio de Janeiro: Seleta.

MACHADO, Nauro (2008). Trindade dantesca. São Luís: edição do autor.

MAGGIE, Yvonne et al. (1992). Medo do feitiço. Rio de Janeiro: Arquivo Nacional.

MERLEAU-PONTY, Maurice (1984). Textos escolhidos. Coleção Os Pensadores. Rio de Janeiro: Abril Cultural.

MICELI, Sergio (2001). Intelectuais à brasileira. São Paulo: Companhia das Letras.

(2003). Nacional estrangeiro: história social e cultural do Modernismo artístico em São Paulo. São Paulo: Companhia das Letras.

MILANO, Dante (1979). Poesia e prosa. Org. e apres. Virgílio Costa. Rio de Janeiro: Civilização Brasileira: Editora da UERJ.

(2004). Dante Milano: obra reunida. Rio de Janeiro: ABL.

NEVES, Thomaz Guilherme Albornoz (1996). Um certo Dante. Dissertação (Mestrado em Letras) - Pontifícia Universidade Católica do Rio de Janeiro, Rio de Janeiro.

SILVA, Vagner Gonçalves da (2012). "Neopentecostalismo e religiões afrobrasileiras: Significados do ataque aos símbolos da herança religiosa africana no Brasil contemporâneo". Mana, v. 13, n. 1, p. 207-236.

SOUSA, Laura de Mello e (2005). O diabo e a Terra de Santa Cruz: feitiçaria e religiosidade popular no Brasil colonial. São Paulo: Companhia das Letras.

TAUSSIG, Michael (1993). Xamanismo, colonialismo e o homem selvagem: um estudo sobre o terror e a cura. Rio de Janeiro: Paz e Terra.

Recebido em maio de 2012.

Aprovado em setembro de 2012. 


\section{resumolabstract}

Análise cultural do torrão dos infernos: imaginário do mal nas poéticas de Dante Milano e Nauro Machado

Alexandre Fernandes Corrêa

O artigo faz uma introdução à análise cultural do imaginário do mal expresso nas obras de dois poetas brasileiros de regiões diferentes do país. Trata-se de um estudo comparativo entre as poesias de Dante Milano (RJ) e Nauro Machado (MA), por meio do qual propomos uma escavação arqueológica dos vestígios da representação do mal no inconsciente social e literário.

Palavras-chave: antropologia, imaginário, literatura, mal, poesia, Dante Milano, Nauro Machado.

Cultural analysis of the homeland of the hells: imaginary of evil in the poetry of Dante Milano and Nauro Machado

Alexandre Fernandes Corrêa

This is an introduction to the cultural analysis of the imaginary of evil expressed in two works by Brazilian poets from different regions of the country. It is a comparative study of the poetry of Dante Milano (RJ) and Nauro Machado (MA), through which we propose an archaeological excavation of the remains of the representation of evil in social and literary unconscious.

Keywords: anthropology, imaginary, literature, evil, poetry, Dante Milano, Nauro Machado. 